\title{
Grouping Strategies for MPS Soot Transport Model and Its Application in Large-Scale Enclosure Fires
}

\author{
XIAOQIN HU, FUCHEN JIA, ZHAOZHI WANG, EDWIN R. GALEA \\ Fire Safety Engineering Group, \\ University of Greenwich, \\ London SE10 9LS UK
}

\begin{abstract}
A soot transport model called Multi-Particle-Size model (MPS model) was developed to improve the prediction of soot movement by considering the uneven mass size distribution of soot particles and the influence of particle size on the gravitational settling. The model requires a sophisticated grouping strategy to divide the soot particles into several groups and determine the representative size for each group. In this paper, several soot particle grouping strategies and the method to calculate the representative sizes are developed with the aim of balancing the computational efficiency and the prediction accuracy of the model. The performance of the MPS model when different grouping strategies are applied is investigated through the comparison of the predicted movement of soot particles generated from several materials. Based on this analysis a grouping strategy that results in the identification of three groups is shown to be sufficient to represent the influence of particle size on the gravitational settling for a variety of combustible materials and the computational cost of the extra governing equations for the transport of soot particles in the groups is acceptable. Furthermore, the efficiency of the model is demonstrated by simulating soot movement in a large-scale industrial building with a high ceiling.
\end{abstract}

KEYWORDS: smoke, CFD model, soot transport model; settling velocity; grouping strategy; large-scale enclosure fire.

\section{NOMENCLATURE LISTING}

$\begin{array}{ll}C r & \text { criterion related to grouping strategy } \\ D_{B} & \text { Brownian diffusion coefficient }\left(\mathrm{m}^{2} / \mathrm{s}\right) \\ D_{m, 0} & \text { particular mass optical density per meter } \\ & \left(\text { ob } \mathrm{m}^{3} / \mathrm{kg}\right) \\ d & \text { particle size }(\mu \mathrm{m}) \\ f_{v} & \text { soot volume fraction } \\ g & \text { magnitude of gravitation acceleration } \\ \mathrm{L} & \text { distance }(\mathrm{m}) \\ m & \text { global mass fractions } \\ T_{o} & \text { ambient temperature }(\mathrm{K}) \\ t & \text { time }(\mathrm{s}) \\ \vec{U} & \text { fluid velocity vector }\end{array}$
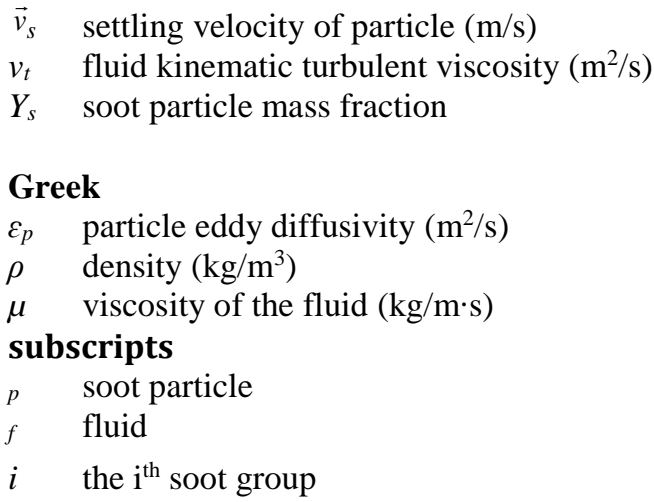

\section{INTRODUCTION}

The detrimental effects of smoke generated from fires to human safety and economic costs have been highlighted in fire safety science. Smoke generated from fires may delay the escape of exposed occupants by reducing the visibility in evacuation routes. Moreover, smoke laden with toxic gases also represents a threat to the occupants. UK fire statistics [1] suggest that the inhalation of smoke alongside with other toxic gases was the main cause of death in fire incidents. In addition, fires in buildings can cause considerable property damage and result in business interruption. Building fire safety heavily relies on the smoke detection system. If a fire occurs, it is desirable that the fire detection and warning system within large buildings provides a sufficiently early warning allowing building occupants to safely evacuate and sufficient time for the fire fighting service to arrive and extinguish the fire before the fire damage is severe. Therefore, it is important for computer simulations to predict smoke layers in fires accurately and efficiently, thus to provide useful information on the design of the fire detection system, ventilation system and building evacuation routes. 
Most soot transport models simply treat soot (the main source of smoke) as being in a gaseous state and the resulting transport equation is the same form as that of other gaseous combustion products [2-6]. The simplification is based on the fact that the majority of soot particles are sized less than $1 \mu \mathrm{m}$ and the movement of those soot particles is similar to that of the gas phase [7]. However, the mass fraction of soot particles larger than $5 \mu \mathrm{m}$ accounts for a non-negligible proportion of the total soot mass for a wide range of combustible building materials [8-11]. Murakami et al. [7] investigated the effect of gravitational settling on particle movement and drew a conclusion that particles larger than $4.5 \mu \mathrm{m}$ behaved in a different way from the gas phase. Treating soot as gaseous state usually leads an under-prediction of the soot levels, especially in the lower layer of an enclosure fire. Therefore, the forces exerted on large particles should be considered in soot transport simulations, in particular within large enclosures. There are many particle transport models which consider the forces exerted on particles [12-17]. One shortcoming of this kind of models is that only one constant size is used to estimate the soot particle velocity while the size of particles may vary in a large range.

To improve the prediction of soot movement in large-scale enclosures, a model called Multi-Particle-Size model (MPS model) was developed by Hu et al. [18]. The model was adopted in the study [19] within the framework of the widely used CFD fire simulation tool FDS to investigate soot deposition on solid surface. The MPS model is an improvement of an Eulerian approach called the drift flux model, by considering the uneven mass size distributions of soot particles and the effect of particle size on gravitational settling. The model divides the soot particles into several groups according to the soot particle mass fraction distribution. Each group contains particles within a size range and a representative size is used to calculate the gravitational settling velocity for each group. The grouping strategy used in the earlier work of Hu et al. [18] simply divided soot particles into three groups with the size ranges of the groups are fixed for all combustible materials. As the mass size distribution of soot particles varies with combustible materials, it is necessary to develop a more accurate grouping strategy to group soot particles of a combustible material in terms of the characteristics of its soot particle size distribution.

This paper first introduces the soot Multi-Particle-Size transport model (MPS model). Then three strategies to group soot particles for the MPS model and the method to calculate the representative sizes are proposed. The performance of the MPS model when different grouping strategies are applied is investigated by simulating soot movement in a two-dimensional chamber. After comparing the predicted movements of soot particles generated from several combustible materials, one of the strategies is recommended as it has the best compromise between the prediction accuracy and the computational cost required. Finally, the MPS model with the recommended grouping strategy is used to simulate the soot movement in a large-scale industrial building with a high ceiling. The simulation results are compared with the experimental measurements and the results predicted by the conventional soot model in which soot is treated as a gas species.

\section{MULTI-PARTICLE-SIZE SOOT TRANSPORT MODEL (MPS MODEL)}

Soot particles are always undergoing Brownian motion, colliding and sticking together in a process known as coagulation. As the soot concentrations in a fire are being continuously diluted by fresh air while soot particles travel from the region near a fire source to a remote location, the coagulation process does not cause a significant change in the characteristics of the soot particle size distribution in a short period of time $[11,20]$. Therefore, the size of a soot particle is assumed to be constant in this study. Generally, the size of soot particles produced in fire ranges from $10^{-2} \mu \mathrm{m}$ to $10 \mu \mathrm{m}$ while most soot particles have size smaller than $1 \mu \mathrm{m}$ [10]. The number of soot particles sized greater than $5 \mu \mathrm{m}$ is usually far less than $0.01 \%$ of the total number of the soot particles generated from the burning of the material concerned. However, the soot mass fraction distribution is different from the soot number size distribution $[8,9,11,21]$.

Figure 1 shows the soot mass fraction distribution against particle size of four building materials derived from [9]. The mass fraction is defined as the ratio of the mass of soot particles of a size class to the total mass of soot particles of all size classes. The soot mass size distributions of the four materials are representative of those of different materials. The mass fraction of particles larger than $5 \mu \mathrm{m}$ is approximately $4 \%$ for soot produced from carbon fibre while it is almost $30 \%$ for soot produced from glass wool and optical cable. For soot produced from polystyrene, the mass fraction for particles larger than 5 $\mu \mathrm{m}$ accounts for more than $40 \%$. Therefore, soot particles sized larger than $5 \mu \mathrm{m}$ accounts for a nonnegligible portion of the total particle mass for many combustible materials. 


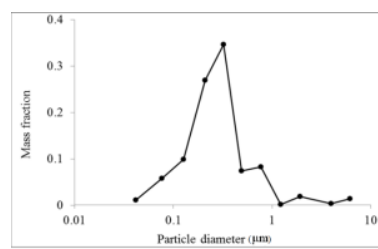

(a)

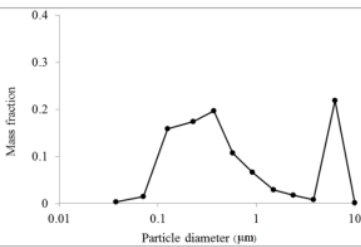

(b)

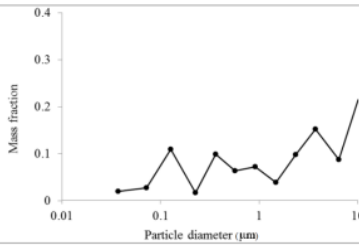

(c)

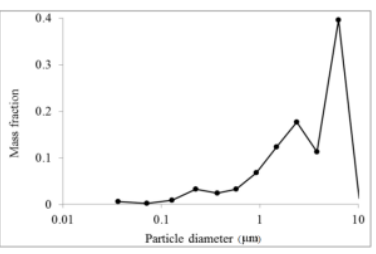

(d)

Fig. 1. Soot mass fraction in terms of soot particles size for (a) carbon fiber, (b) optical cable, (c) glass wool, and (d) polystyrene (reproduced from the work in [9]).

The movement of particles in an indoor environment is influenced mainly by gravitational force, buoyancy force and drag force. Other forces such as pressure gradient force are negligible according to the work of Zhao et al. [14]. The three forces gradually reach a balance in a homogeneous surrounding medium, thus the particle reaches a constant velocity relative to its surrounding. This constant velocity is called terminal velocity or settling velocity [22]. The settling velocity has the same direction as the gravity. If the particles are spheres and the particle Reynolds number is less than 1.0, the magnitude of the settling velocity is calculated as [23-24]:

$\left|\vec{v}_{s}\right|=\frac{g\left(\rho_{p}-\rho_{f}\right) d_{p}^{2}}{18 \mu}$

where $\rho_{p}$ and $\rho_{f}$ are the densities of particles and fluid respectively. $\mu$ is viscosity of the fluid. Eq. 1 shows that the magnitude of settling velocity $\vec{v}_{s}$ strongly depends on the particle size $d_{p}$. The settling velocities are approximately $10^{-5} \mathrm{~m} / \mathrm{s}$ for particles sized of $1 \mu \mathrm{m}$, which can be ignored compared with the velocity of the air flow within fire enclosures. However, the settling velocity of larger particles cannot be completely ignored. For example, the settling velocities are approximately $10^{-4} \mathrm{~m} / \mathrm{s}$ for particles sized $2 \mu \mathrm{m}$ and $10^{-3}$ $\mathrm{m} / \mathrm{s}$ for particles sized $5 \mu \mathrm{m}$. This velocity magnitude is comparable with the velocity in the gravitational direction of gas flow in the remote locations in fire enclosures and should be considered in soot particle transport modelling.

The drift flux model $[14,25,26]$, which is an Eulerian approach, considers the gravitational settling influence of particles by adding a drift term into the convection term in the particle transport governing equation. In this study, the drift flux model was applied to investigate the influence of settling velocity on particle movement with two different soot particle sizes $(1 \mu \mathrm{m}$ and $10 \mu \mathrm{m})$ in a two-dimensional chamber. The geometry of the chamber was $30 \mathrm{~m}$ (length) $\times 10 \mathrm{~m}$ (height). There were no fans or ventilation in the chamber. A simple fire with size $30 \mathrm{~m} \times 1 \mathrm{~m}$ was placed under the ceiling. The fire had a constant heat release rate of $10 \mathrm{KW} / \mathrm{s}$ and soot release rate of $0.0025 \mathrm{~kg} / \mathrm{s}$ for the first 100 seconds. The predicted concentration of soot was normalised by a maximum concentration of $8.04 \times 10^{-3} \mathrm{~kg} / \mathrm{m}^{2}$ within the chamber. Figure 2 shows the normalised soot concentrations along the vertical central line of the chamber. Almost no particles sized $1 \mu \mathrm{m}$ reached the lower layer even after 1800 seconds while most soot particles sized $10 \mu \mathrm{m}$ moved downwards to approximately $8 \mathrm{~m}$ height within a short period of time $(180 \mathrm{~s})$ and deposited on floor after $1800 \mathrm{~s}$. This demonstrates that settling velocity plays an important role in soot particle transport. Therefore, the settling velocities of large soot particles must be considered as they may account for a significant fraction of the total mass of soot particles.

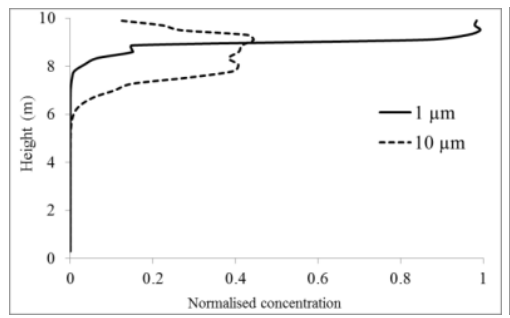

(a)

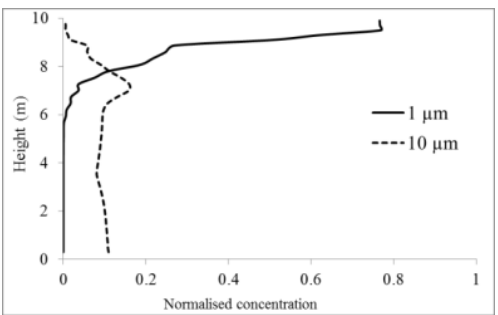

(b)

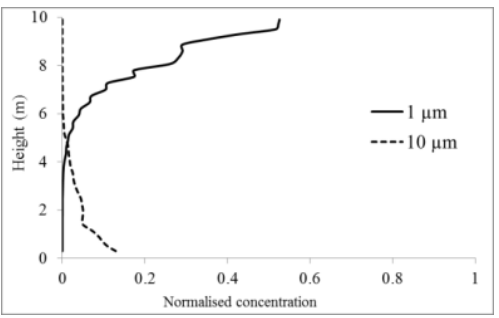

(c)

Fig. 2. The normalised soot concentration along the central vertical line at (a) $180 \mathrm{~s}$, (b) $600 \mathrm{~s}$, (c) $1800 \mathrm{~s}$. 
The foregoing discussion shows that it is necessary to consider the effect of settling velocity on soot particle movement. As the sizes of soot particles vary in a large range, it is not adequately accurate to represent the settling velocities for all individual soot particles with just one single size. An improvement of the drift flux model, called Multi-Particle-Size (MPS) model, was developed to simulate soot transport [18]. First, the MPS model divides the soot particles into several groups based on a grouping strategy. Then for each group, a representative soot size is used to calculate the settling velocity of the group. The transport of the soot particles in the $\mathrm{i}^{\text {th }}$ group is defined by a governing equation:

$$
\frac{\partial \rho \mathrm{Y}_{\mathrm{s}, \mathrm{i}}}{\partial \mathrm{t}}+\operatorname{div}\left(\rho\left(\overrightarrow{\mathrm{U}}+\overrightarrow{\mathrm{v}}_{\mathrm{s}, \mathrm{i}}\right) \mathrm{Y}_{\mathrm{s}, \mathrm{i}}\right)=\operatorname{div}\left(\rho\left(\mathrm{D}_{\mathrm{B}}+\varepsilon_{\mathrm{p}}\right) \nabla \mathrm{Y}_{\mathrm{s}, \mathrm{i}}\right)+\mathrm{S}_{\mathrm{Y}_{\mathrm{s}, \mathrm{i}}}
$$

where $Y_{s, i}$ denotes the mass fraction of the $\mathrm{i}^{\text {th }}$ soot group, the settling velocity $\vec{v}_{s, i}$ of particles is determined by Eq. 1 with the representative particle size of the group, The particle eddy diffusivity $\varepsilon_{p}$ is assumed to equal the fluid turbulent viscosity, $v_{t}$, in enclosed fire environments for soot particles [27]. The model ignores the effect of particles on turbulence as it is believed that the low particle loadings have a negligible effect compared to the high flow turbulence levels [28].

The total soot mass fraction, $Y_{S}$, is then given by:

$Y_{S}=\sum Y_{S, i}$

In a previous study, Hu et al. [18] simply divided the soot particles into three groups namely, particles sizes less than $2.0 \mu \mathrm{m}$, between $2.0 \mu \mathrm{m}$ and $7.0 \mu \mathrm{m}$ and larger than $7.0 \mu \mathrm{m}$. As the characteristics of the mass size distributions vary significantly among combustible materials, the grouping strategy with fixed size ranges for all materials is crude. A more accurate grouping strategy is required in the further application of the MPS model.

\section{SOOT PARTICLE GROUPING STRATEGIES}

In experiments, soot particles are collected and assigned into $n$ classes according to their sizes (see Fig. 1). The $i^{\text {th }}$ class contains soot particles sized within a small range and a size $d_{i}$ is used to represent the size of the class. The mass distribution against size for combustible materials can be found in publications $[8,9$, $11,29,30]$. While the prediction of soot particle movement is accurate if all soot particle classes are considered, the computational expense becomes unacceptable. In this section, several soot particle grouping strategies applied in the MPS model are discussed by taking into account computational efficiency and prediction accuracy.

To facilitate the discussion on grouping strategy, the sizes for all classes are assumed to be $d_{1}, d_{2}, \cdots, d_{n}$ $\left(d_{1}>d_{2}>\cdots>d_{n}\right)$ and the corresponding global mass fractions are $m_{1}^{0}, m_{2}^{0}, \cdots, m_{n}^{0}\left(\sum_{i=1}^{n} m_{i}^{0}=1\right)$, which are supposed to be constants as the changes in soot mass size distribution are ignored. The density of soot particle is also assumed to be a constant.

\section{Method 1}

The simplest method of grouping soot particles is to assign them to one single group (the mass fraction is 1) with a representative size $\bar{d}$ to quantify the effect of gravitational settling on soot movement. Assume the total mass of soot particles in a control volume is $m$. The momentum of the representative particles with size $\bar{d}$ should be equal to the total momentum of all classes:

$$
m \overline{\vec{v}}_{s}=\sum_{i=1}^{n}\left(m m_{i}^{0}\right) \vec{v}_{s, i}
$$


where $\overline{\vec{v}}_{s}$ and $\vec{v}_{s, i}$ are the settling velocities for soot particles of size $\bar{d}$ and $d_{i}$ respectively. Substituting of Eq. 1 into Eq. 4, the representative size can be calculated as:

$\bar{d}^{2}=\sum_{i=1}^{n} m_{i}^{0} d_{i}^{2}$

The representative soot size calculated by Eq. 5 is valid only if the soot mass fractions of all classes in the control volume at any instant are the same as the global mass fractions. However, the mass fractions of soot classes in a control volume always vary during the soot movement.

\section{Method 2}

The validity of Method 1 becomes questionable for a material that produces soot particles with a large variation in size. It can be very crude to have one single group to represent all soot particles in this situation. It is more accurate to use settling velocities calculated from several representative sizes to describe the soot movement.

First the determination of the representative size of a group is addressed. If soot particle classes with sizes $d_{k}, d_{k+1}, \cdots, d_{k+p}\left(d_{k}>d_{k+1}>\cdots>d_{k+p}\right)$ and corresponding mass fractions $m_{k}^{0}, m_{k+1}^{0}, \cdots, m_{k+p}^{0}$ are assigned to one group, the representative size of the group, $\bar{d}_{k}$, can be calculated by an equation similar to Eq. 5 :

$$
\bar{d}_{k}^{2}=\sum_{j=k}^{k+p} m_{j}^{0} d_{j}^{2} / \sum_{j=k}^{k+p} m_{j}^{0}
$$

The way of grouping soot particles should guarantee that the settling velocity calculated from the representative size of a group can be used to quantify the soot momentum of the group with a reasonable accuracy. One approach is to restrict the soot particle size range of the group so that there is no great variation in the particles' settling velocities among the group. Assume an additional soot class with a smaller size $d_{q}\left(d_{q}<\bar{d}_{k}\right)$ and mass fraction $m_{q}^{0}$ is merged into the current group. The mass fraction of the newly added soot particle class in the whole new group is

$$
m_{q}^{*}=\frac{m_{q}^{0}}{m_{q}^{0}+\sum_{j=k}^{k+p} m_{j}^{0}}
$$

Then the mass fraction of the original group in the new group is $1-m_{q}{ }^{*}$. The representative size $\bar{d}_{k}^{*}$ of the new group is calculated by Eq. 6 and simplified as:

$$
\bar{d}_{k}^{* 2}=m_{q}^{*} d_{q}^{2}+\left(1-m_{q}^{*}\right) \bar{d}_{k}^{2}
$$

The criterion related to the change of the representative size is defined as:

$$
C r_{1}=\bar{d}_{k}-\bar{d}_{k}^{*}<t_{1}
$$

where $t_{1}$ is a given tolerance. For particles smaller than $5 \mu \mathrm{m}, C r_{1} \leq 1 \mu \mathrm{m}$ is acceptable as the change in the representative settling velocity is less than $5 \times 10^{-4} \mathrm{~m} / \mathrm{s}$. Similarly, for particles smaller than $10 \mu \mathrm{m}$ and larger than $5 \mu \mathrm{m}, C r_{1} \leq 0.5 \mu \mathrm{m}$ is acceptable.

However, it is difficult to avoid a great variation in settling velocities among the group if the sizes of particles are very large. For example, $1 \mu \mathrm{m}$ difference in size can cause a difference of $10^{-3} \mathrm{~m} / \mathrm{s}$ in settling 
velocity if the sizes of soot particles are larger than $9 \mu \mathrm{m}$. Therefore, when there is a large variation in settling velocity among the group and the first criterion is not met, a second criterion is sought to restrict the error in the estimation of the soot particle momentum (usually for particles larger than $5 \mu \mathrm{m}$ ) so that the under-estimation of the soot momentum of the group should be within an acceptable tolerance. Assume that the total soot mass of the group in a control volume is $m_{g k}$. As the settling velocities among one group are always no more than the settling velocity $\vec{v}_{s, k}$ (calculated from largest soot particle with size $d_{k}$ in the group), it is always true that:

$$
1 \geq \frac{m_{g k} \overrightarrow{\vec{v}}_{s, k}}{m_{g k} \vec{v}_{s, k}}=\frac{\overline{\vec{v}}_{s, k}}{\vec{v}_{s, k}}=\frac{\bar{d}_{k}^{2}}{d_{k}^{2}}
$$

where $\overline{\vec{v}}_{s, k}$ is the settling velocity of a particle with the representative size of the group $\bar{d}_{k}$. The above inequality shows that the larger the ratio, $\bar{d}_{k}^{2} / d_{k}^{2}$, is, the less the momentum of the group is under-estimated if the settling velocity is calculated from the representative size $\bar{d}_{k}$. Define the second criterion $\mathrm{Cr}_{2}$ as follows

$$
C r_{2}=1-\bar{d}_{k}^{2} / d_{k}^{2}<t_{2}
$$

$\mathrm{Cr}_{2}$ should be smaller than a given tolerance $t_{2}$ so that the momentum of the group is not severely underestimated. Here $t_{2}$ is set to be 0.3 .

For soot particles smaller than $1.5 \mu \mathrm{m}$, the magnitude of settling velocity is $10^{-5} \mathrm{~m} / \mathrm{s}$. The effect of gravitational settling on these particles can be ignored. Thus grouping these small soot particles without considering the above two criteria is reasonable.

Based on the above discussion, a method to group the soot particles is developed and the procedure is outlined as follows:

Step 1: Sort the ungrouped soot particles by size from largest to smallest. This results in soot classes as $d_{l}$, $d_{2}, \cdots, d_{n}\left(d_{1}>d_{2}>\cdots>d_{n}\right)$ and the corresponding global mass fractions for these classes are $m_{1}^{0}, m_{2}^{0}, \cdots, m_{n}^{0}\left(\sum_{i=1}^{n} m_{i}^{0}=1\right)$;

Step 2: Set $k=q=1$;

Step 3: If $d_{q}<1.5 \mu \mathrm{m}$, go to step 6; otherwise, set $\mathrm{S}_{\mathrm{k}}=\left\{d_{q}\right\}$ and $\bar{d}_{k}=d_{q}$. Set $\mathrm{q}=\mathrm{q}+1$. If $q \leq n$, go to step 4 . Otherwise go to step 7.

Step 4: Add the soot class with size $d_{q}$ to $S^{\prime}{ }_{k}=S_{k} \bigcup\left\{d_{q}\right\}$, calculate the criteria $C r_{1}$ (Eq. 9) and $C r_{2}$ (Eq. 11) over S' ${ }_{k}$.

If $\left(d_{q} \geq 5 \mu \mathrm{m}\right)$ and $\left(C r_{1}<0.5 \mu \mathrm{m}\right.$ or $\left.C r_{2}<30 \%\right)$, add the soot class $q$ to group k, i.e., $\mathrm{S}_{\mathrm{k}}=\mathrm{S}_{\mathrm{k}} \bigcup\left\{d_{q}\right\}$.

Go to step 5;

If $\left(d_{q}<5 \mu \mathrm{m}\right)$ and $\left(C r_{1}<1 \mu \mathrm{m}\right.$ or $\left.C r_{2}<30 \%\right)$, add the soot class $q$ to group k, i.e., $\mathrm{S}_{\mathrm{k}}=\mathrm{S}_{\mathrm{k}} \bigcup\left\{d_{q}\right\}$.

Go to step 5;

Otherwise, set $\mathrm{k}=\mathrm{k}+1$, go to step 3

Step 5: Calculate the representative size of $S_{k}$ by Eq. 6 . Set $q=q+1$; go to step 4;

Step 6: Combine all the remaining classes into one group as $S_{k}$ and get the representative size by Eq. 6 .

Step 7: Stop.

\section{Method 3}

Method 2 does not limit the number of the groups and hence the potential computational cost may be high. Here a strategy to further reduce the number of soot groups is developed. First, the soot particles are grouped by Method 2. If the number of the soot groups is greater than 3, some groups with small mass fractions are merged to reduce the number of the groups. If a group with large soot particles (representative 
size $>5 \mu \mathrm{m})$ has a small mass fraction $(<0.05)$, or if a group with the representative soot particle smaller than $5 \mu \mathrm{m}$ has a mass fraction less than 0.1 , the group is merged into the next group which has a smaller representative size.

Method 2 normally divides the soot particles produced from the burning of the combustible materials studied in [9] into 3 groups, while for a few of the materials 4 or 5 groups are required. Using Method 3, the soot particles from all of these materials are divided into 3 groups [20]. The grouping results for four materials using the three methods are presented in Table 1. In practice, the computational cost is acceptable if the number of groups is no more than 3.

Table 1. The soot groups derived from Method 1, Method 2 and Method 3 for four representative materials

\begin{tabular}{|c|c|c|c|c|c|c|}
\hline \multirow[b]{2}{*}{ Material } & \multicolumn{2}{|c|}{ Method 1} & \multicolumn{2}{|c|}{ Method 2} & \multicolumn{2}{|c|}{ Method 3} \\
\hline & $\begin{array}{c}\text { Representative } \\
\operatorname{size}(\mu \mathrm{m})\end{array}$ & $\begin{array}{c}\text { Mass } \\
\text { fraction }\end{array}$ & $\begin{array}{c}\text { Representative } \\
\text { size }(\mu \mathrm{m})\end{array}$ & $\begin{array}{l}\text { Mass } \\
\text { fraction }\end{array}$ & $\begin{array}{c}\text { Representative } \\
\operatorname{size}(\mu \mathrm{m})\end{array}$ & $\begin{array}{c}\text { Mass } \\
\text { fraction }\end{array}$ \\
\hline \multirow{3}{*}{ Carbon fibre } & \multirow[b]{3}{*}{2.1838} & \multirow[b]{3}{*}{1} & 7.19 & 0.0385 & 7.19 & 0.0385 \\
\hline & & & 1.21 & 0.0207 & 1.21 & 0.0207 \\
\hline & & & 0.32 & 0.9408 & 0.32 & 0.9408 \\
\hline \multirow{3}{*}{ Glass wool } & \multirow[b]{3}{*}{5.3152} & \multirow[b]{3}{*}{1} & 9.17 & 0.3026 & 9.17 & 0.3026 \\
\hline & & & 3.07 & 0.2895 & 3.07 & 0.2895 \\
\hline & & & 0.29 & 0.4079 & 0.29 & 0.4079 \\
\hline \multirow{4}{*}{$\begin{array}{l}\text { Optical } \\
\text { cable }\end{array}$} & \multirow[b]{4}{*}{3.0563} & \multirow[b]{4}{*}{1} & 10.00 & 0.002 & \multirow[b]{2}{*}{6.09} & \multirow[b]{2}{*}{0.2469} \\
\hline & & & 6.04 & 0.2449 & & \\
\hline & & & 0.88 & 0.2039 & 0.88 & 0.2039 \\
\hline & & & 0.12 & 0.5422 & 0.12 & 0.5422 \\
\hline \multirow{3}{*}{ Polystyrene } & \multirow{3}{*}{4.4617} & \multirow{3}{*}{1} & 10.15 & 0.0135 & 10.15 & 0.0135 \\
\hline & & & 5.15 & 0.6863 & 5.15 & 0.6863 \\
\hline & & & 0.62 & 0.3022 & 0.62 & 0.3022 \\
\hline
\end{tabular}

\section{Performance of the Grouping Strategies}

In order to examine the performance of these grouping strategies, the movement of soot particles from four building materials (listed in Fig. 1) had been simulated in a 2-dimensional closed chamber, which was described in the section Multi-particle-size soot transport model. Four simulations for each of the four materials were carried out for $1800 \mathrm{~s}$ with different grouping strategies. First, all the 12 soot classes identified from the fire experiments (see Fig. 1) were applied in the simulation for each material. Then the soot groups derived by Method 1, 2 and 3 were applied (see Table 1). In order to examine the reliability and accuracy of the three soot grouping strategies, the predicted soot concentrations along the vertical central line were compared with the results predicted with the original classes (Fig. 3-6). The soot concentrations are normalised by the value $8.04 \times 10^{-3} \mathrm{~kg} / \mathrm{m}^{2}$.

The soot particles sized less than $1 \mu \mathrm{m}$ account for more than $90 \%$ of soot mass for carbon fibre (Fig. 1(a)). The representative size derived using Method $1(2.1835 \mu \mathrm{m})$ is at least twice as large as most soot particles produced from the material. Using the settling velocity calculated from this method overestimated the sedimentation of most soot particles. Compared with the prediction using the 12 original classes, the soot concentration at $0.5 \mathrm{~m}$ below the ceiling was under-predicted $12.3 \%$ at $600 \mathrm{~s}, 28.2 \%$ at $1200 \mathrm{~s}$ and $39.6 \%$ at $1800 \mathrm{~s}$ when Method 1 was applied (Fig. 3). The soot particles produced from optical cable and glass wool have more even mass size distributions compared with those of the other two materials (Fig. 1(b) and (c)). For glass wool, the soot concentration was under-predicted $53.5 \%$ at the height of $0.5 \mathrm{~m}$ below the ceiling, over-predicted $98.5 \%$ at the height of $3 \mathrm{~m}$ below the ceiling, and under-predicted $99 \%$ at the height of $1 \mathrm{~m}$ 
above the floor just after $600 \mathrm{~s}$ simulation time when Method 1 was applied (Fig. 5). The discrepancy between the predictions from Method 1 and the predictions using the 12 original classes is also obvious for optical cable (Fig. 4). For polystyrene, after $1200 \mathrm{~s}$, the soot concentration at the height of $1 \mathrm{~m}$ above the floor reaches $3.5 \%$ using the 12 original classes while it is near zero predicted by Method 1 . For all the four materials representative of different types of soot mass size distribution, Method 1 produced large errors in the predictions of soot concentration compared with the predictions by all the original soot classes. This suggests that using one representative soot size does not result in sufficient accuracy to describe the settling velocities for soot particles of all different sizes. It also demonstrates that gravitational settling plays a significant role in soot movement.

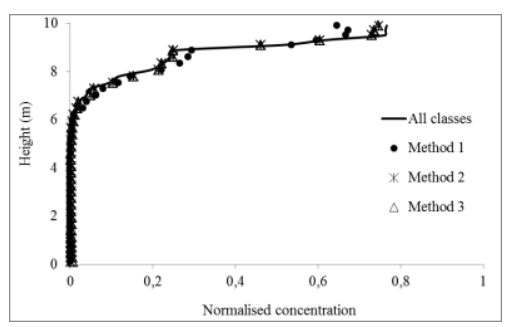

(a)

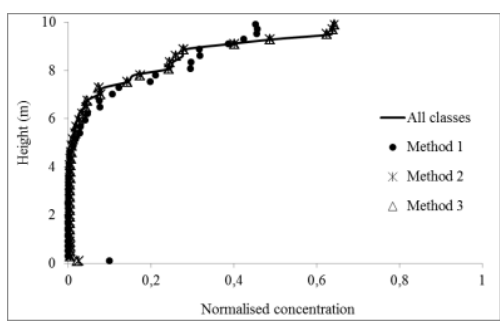

(b)

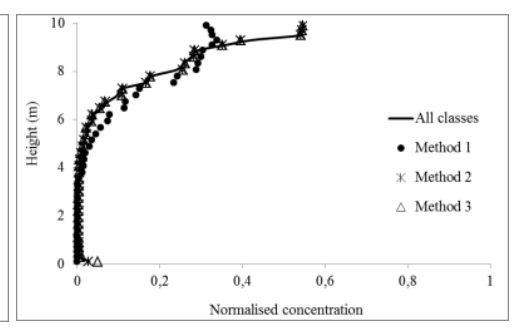

(c)

Fig. 3. Normalized soot concentration for carbon fibre at (a) $600 \mathrm{~s}$, (b) $1200 \mathrm{~s}$ and (c) $1800 \mathrm{~s}$.

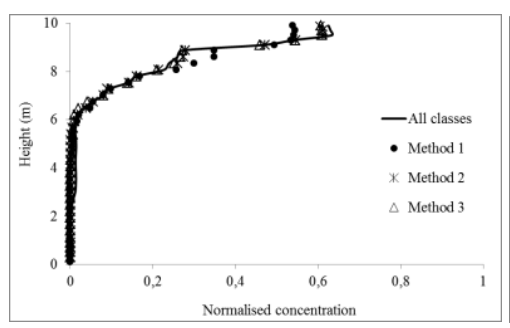

(a)

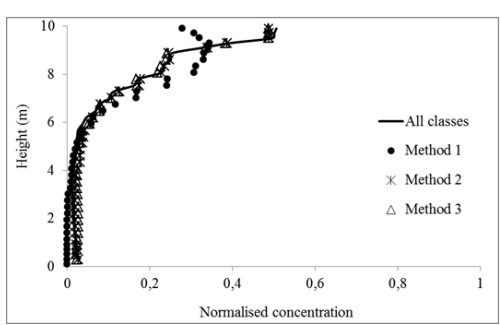

(b)

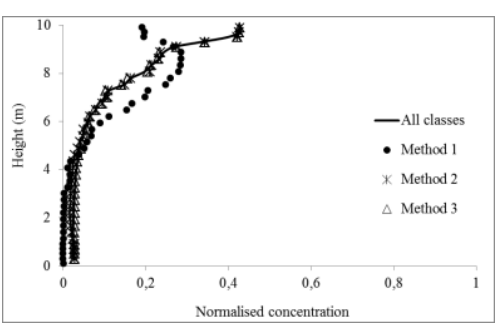

(c)

Fig. 4. Normalised soot concentration for optical cable at (a) $600 \mathrm{~s}$, (b) $1200 \mathrm{~s}$ and (c) $1800 \mathrm{~s}$.

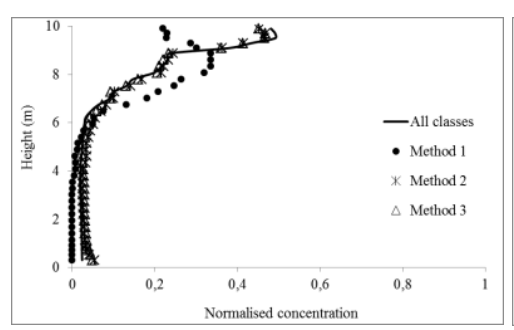

(a)

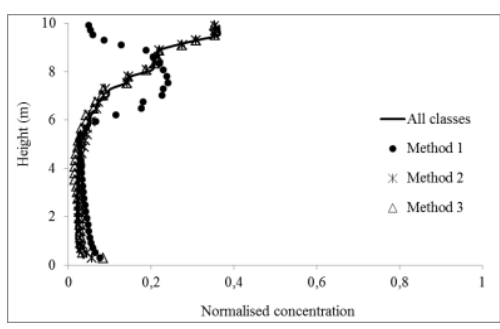

(b)

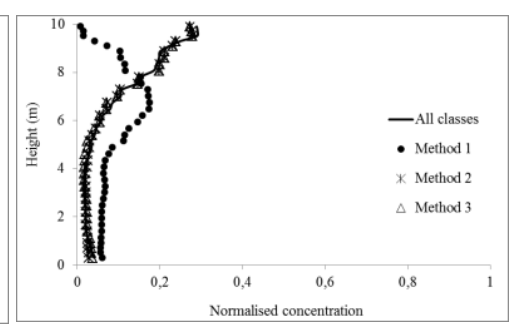

(c)

Fig. 5. Normalised soot concentration for glass wool at (a) $600 \mathrm{~s}$, (b) $1200 \mathrm{~s}$ and (c) $1800 \mathrm{~s}$.

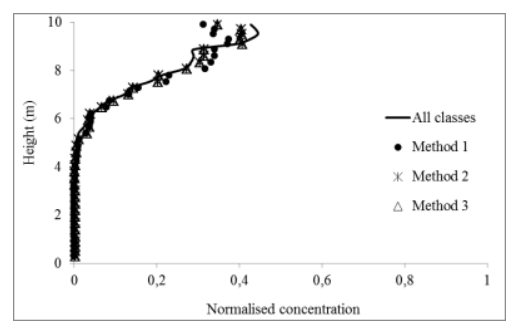

(a)

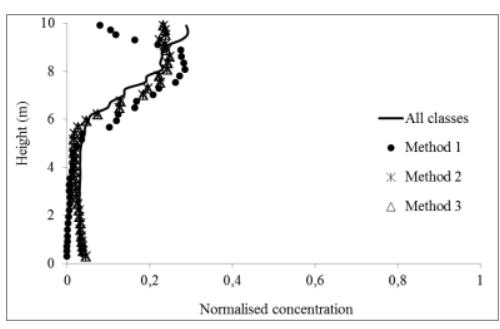

(b)

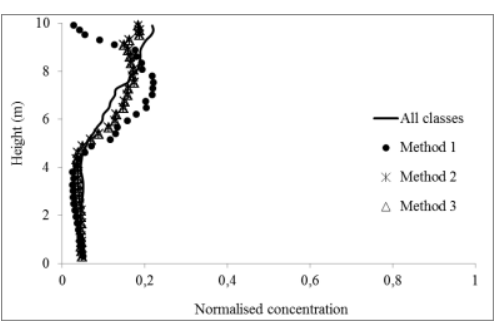

(c)

Fig. 6. Normalised soot concentration for polystyrene at (a) $600 \mathrm{~s}$, (b) $1200 \mathrm{~s}$ and (c) $1800 \mathrm{~s}$.

However, the soot concentrations predicted using Method 2 and Method 3 are much closer to those predicted using the 12 original classes during the whole simulation period (1800 seconds) for the four materials. Comparing the predicted soot concentration using all original classes and using Method 2 and 3, 
the maximum difference is no more than $5 \%$ for the first three materials and is approximately $15 \%$ for polystyrene. For optical cable, although the group division derived from Method 2 is not the same as that from Method 3, the difference in predictions derived from the two grouping strategies is no more than $3 \%$. This demonstrates that Method 3 can reduce the group numbers without greatly reducing prediction accuracy.

\section{SIMULATING SOOT TRANSPORT IN A LARGE-SCALE INDUSTRY BUILDING}

In this section, soot movement in a large-scale industry building was simulated using the MPS model and the Conventional Model in which soot is treated as a gas species. The predictions of soot obscuration at some points of the building are compared with the measurements.

\section{Experiments and measurements}

A series of experiments in which soot obscuration was measured were conducted in a large industry building. During the experiments, a soot generator releasing diesel soot particles was placed on the floor of the industry building [31]. The building was a large-scale enclosure with a floor size of $171 \times 90 \mathrm{~m}^{2}$ and height of $7.25 \mathrm{~m}$. The temperature within the building varied between 23 and $26^{\circ} \mathrm{C}$. The experiments were performed during normal operation of the facility, which means the experiments were not fully controlled. The building was equipped with optical point detectors and lasers with a wavelength of $670 \mathrm{~nm}$. The laser measured over one meter while the detector measured in a single point. The origin of the coordinates was defined as the position that was $7 \mathrm{~m}$ away from the soot source in $x$ direction and $6 \mathrm{~m}$ away from the soot source in $y$ direction at floor level. The locations of the soot source and some items of the experimental equipment are given in Table 2.

Table 2. Coordinates of the equipment and the soot source.

\begin{tabular}{|c|c|c|}
\hline Instrument/fire & coordinates & Comments \\
\hline Soot generator & $(7,6,0)$ & $\begin{array}{l}\text { Soot release rate }=10 \mathrm{~g} / \mathrm{s} \quad \text { if } \mathrm{t} \leq 10 \mathrm{~s} \\
\text { Soot release rate }=0.1+(t-10) \times 0.02 \mathrm{~g} / \mathrm{s} \text { if } 10 \mathrm{~s}<\mathrm{t} \leq 360 \mathrm{~s} \\
\text { (based on the simulation of Blomqvist [31]) }\end{array}$ \\
\hline Detector I & $(11.25,6,6.2)$ & \multirow{2}{*}{ Optical point detectors APS006 } \\
\hline Detector II & $(15.75,6,6.2)$ & \\
\hline Laser 1 & $(7.4,5.7,4.8)$ & \multirow{3}{*}{$\begin{array}{l}\text { All laser beams were parallel to the floor. The } \\
\text { coordinates are the position of the midpoint of a laser } \\
\text { beam, which was the most closed point to the soot } \\
\text { source in the beam. }\end{array}$} \\
\hline Laser 2 & $(6.3,10.7,6.25)$ & \\
\hline Laser 3 & $(10.8,10.7,6.25)$ & \\
\hline
\end{tabular}

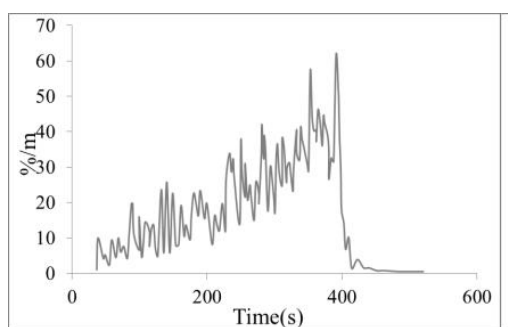

(a)

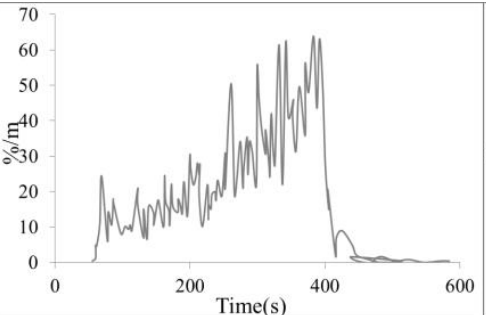

(b)

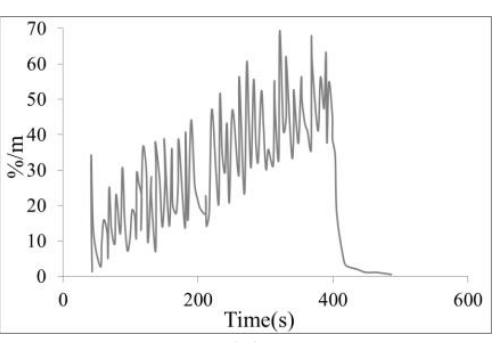

(c)

Fig. 7 The measured soot obscuration by laser 1 for (a) test 1, (b) test 2 and (c) test 3 [31].

The experiment was repeated three times. Although the normal operation within the facility caused discrepancy in measured data between the tests, some measurements still have the similar tendency among the repeat tests, including the obscuration tendency measured by the three lasers and two detectors. Some conclusions of the experimental results are presented as follows:

- Detectors I and II gave warning and pre-alarmed activation in the three repeat tests, which indicated the soot obscuration at the two positions should be greater than $2 \% / \mathrm{m}$ at some times.

- Detector I and II recorded a similar tendency of soot obscuration in the three tests. 
- There are great fluctuations in the soot obscuration measured by the lasers, especially for laser 1 (see Fig. 7). For each laser, the measured soot obscuration in the three repeat tests follows a similar tendency.

\section{Numerical details}

Blomqvist [31] had run a series of simulations of the experiments. The simulation set-up in this study was very similar to that of the Blomqvist's simulations, as there was a lack of information of the experiment, such as the soot release rate and velocity and disturbances caused by the normal operation at the facility.

The computational region was a cuboid of $20 \mathrm{~m} \times 15 \mathrm{~m}$ with a height of $7.3 \mathrm{~m}$, a cut-out space within the building. A non-uniform mesh consisting of 192,000 cells was applied to discretise the region and the largest mesh size was around $0.3 \times 0.3 \times 0.2 \mathrm{~m}^{3}$. The four vertical boundaries of the cuboid were set to be free flow (outlet) and the temperature was assumed to be constant with a value of $297 \mathrm{~K}$. The soot source was modelled as an inlet on the floor, with a constant inlet velocity of $1.5 \mathrm{~m} / \mathrm{s}$ through a $0.2 \mathrm{~m}$ squared hole at temperature $340 \mathrm{~K}$. The simulations were carried out with a time step size of 2 second for 600 seconds.

The MPS model was used in one simulation to simulate the soot transport in the building and the Conventional Model in which soot is treated as a gas species was used in another simulation. For the simulation using the MPS model, the soot mass fraction distribution of diesel [32] was used because the fuel used in the soot generator was diesel [33]. The group divisions calculated using Method 3 are listed in Table 3.

Table 3. Soot particle groups

\begin{tabular}{|l|c|c|c|}
\hline Representative size $(\boldsymbol{\mu m})$ & 15.4643 & 2.8052 & 0.2021 \\
\hline Mass fraction & 0.0553 & 0.1050 & 0.8397 \\
\hline
\end{tabular}

\section{Simulation results and discussion}

In this section, the soot obscuration profiles on a vertical cut plane predicted by the MPS model and the Conventional Model are compared. Further, the predicted obscuration tendencies at positions of two detectors and three lasers are compared with the measurements.

\section{Obscuration profile}

The obscuration per meter is calculated as [20][31]:

obscuration per meter $(\% / \mathrm{m})=100\left(1-10^{-\frac{1.9 \times 10^{4} \times 1.8 \times 10^{3} f_{v}}{10}}\right)$

Equation 12 is derived by simplifying the obscuration equation in [34] with the soot density $\rho_{s}=1800 \mathrm{~kg} / \mathrm{m}^{3}$, the particular mass optical density per meter $D_{m, 0}=1.9 \times 10^{4} \mathrm{ob} \mathrm{m}^{3} / \mathrm{kg}$, and the distance $\mathrm{L}$ to be unit length.

To have an overview on the soot movement, the obscuration distribution on the vertical cut XZ-plane across the soot source is displayed in Fig. 8. The soot generator released soot continually and was stopped at $360 \mathrm{~s}$. Soot was predicted to spread under the ceiling by both models. However, Fig. 8 shows that there is a considerable difference in the predicted soot obscuration produced using the two models in the region 0.8 $\mathrm{m}$ below the ceiling. The obscuration in this region was predicted to be near zero by the Conventional Model during the entire simulation time. However, the obscuration in this region was predicted by the MPS model to decrease gradually with time and the obscuration value in most of the region was near or over 1 $\% / \mathrm{m}$ after $390 \mathrm{~s}$. This corresponds to the experimental observation that a layer of soot was hanging in the air and moving downwards to the people working in the building during the experiments. 


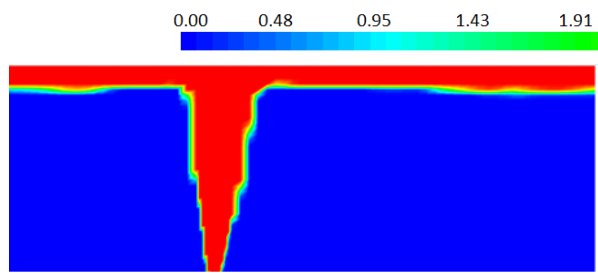

(a)

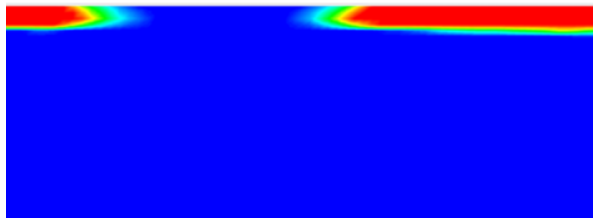

(c)

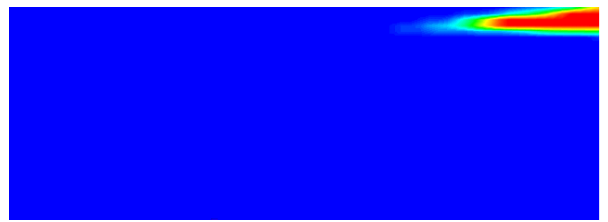

(e)

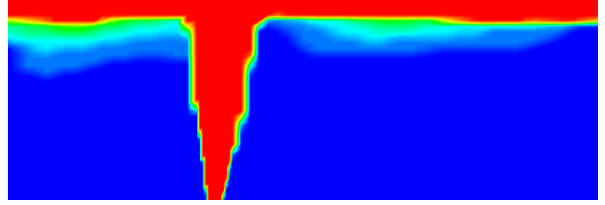

(b)

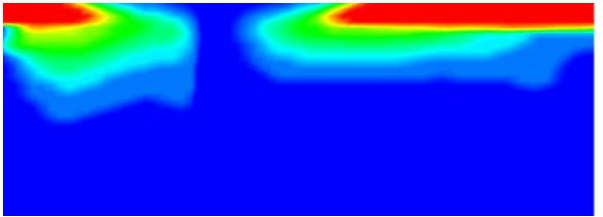

(d)

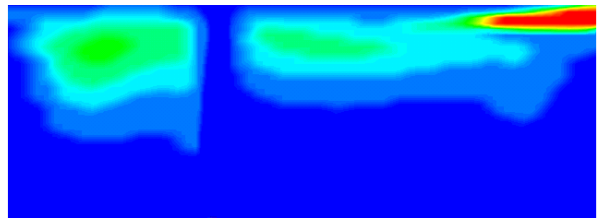

(f)

Fig. 8. The predicted obscuration profile at the vertical cut plane across the soot source at (a) $300 \mathrm{~s}$, (c) 390 s, (e) $480 \mathrm{~s}$ using the Conventional Model and at (b) $300 \mathrm{~s}$, (d) $390 \mathrm{~s}$, (f) $480 \mathrm{~s}$ using the MPS model.

\section{Obscuration at laser positions}

Laser 1 was mounted $2.5 \mathrm{~m}$ below the ceiling while Laser 2 and Laser 3 were both mounted $1.1 \mathrm{~m}$ below the ceiling. The obscuration derived from the measurements of the three lasers in the three repeat tests shows great fluctuations, but has a similar tendency. The measured obscuration tendency from test 2 is used to compare with the predictions as the results from this test are more stable than the other two. Fig. 9 shows the soot obscuration tendencies derived from the measurements of the three lasers and calculated from the predictions of the two models. In order to include the information of the obscuration fluctuations, the upper and lower bound in the measured obscuration in every 30 seconds are also presented (vertical lines).

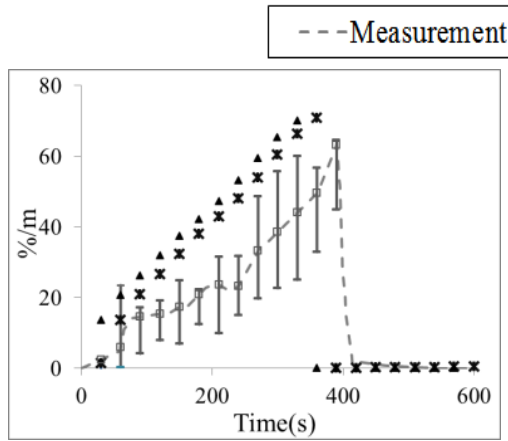

(a)

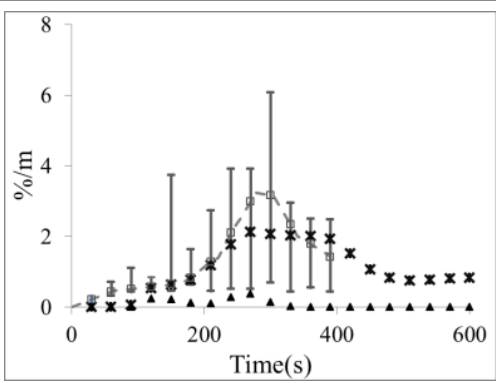

(b)

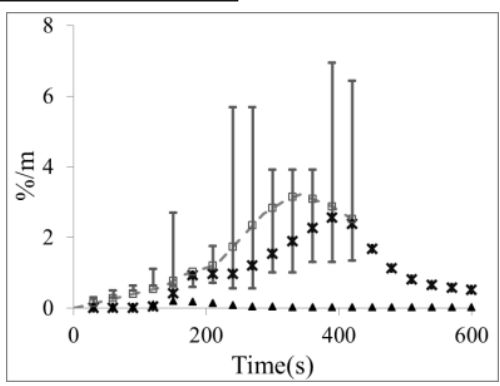

(c)

Fig. 9. The measured and predicted obscuration tendency at the position of (a) Laser 1, (b) Laser 2, (c)Laser 3.

The obscuration tendencies predicted by both models matches the measured tendency at the position of Laser 1. However, both models over-estimated the obscuration at this position. The reason might be that the soot concentration at the height of the laser was easily diluted by the air flow which was caused by the normal operations within the building and was not simulated in the study. The measurements at positions of Laser 2 and Laser 3 show that the soot obscuration tendencies at the two positions increased in the first 300 seconds. The MPS model predicted the tendency reasonably well while the Conventional Model failed to 
predict this trend. The peak obscuration predicted by the Conventional Model is approximately zero, which is outside the range of the measured obscuration fluctuations.

\section{Obscuration at detector positions}

Detector I and II were both mounted $1.1 \mathrm{~m}$ below the ceiling. Figure 10 shows the tendency of soot obscuration measured by the detectors and calculated from the predictions of the MPS model and the Conventional Model. The measured tendencies (dash lines), the upper and lower bounds of the measured obscuration in every 30 seconds (vertical lines) are derived from test 2.

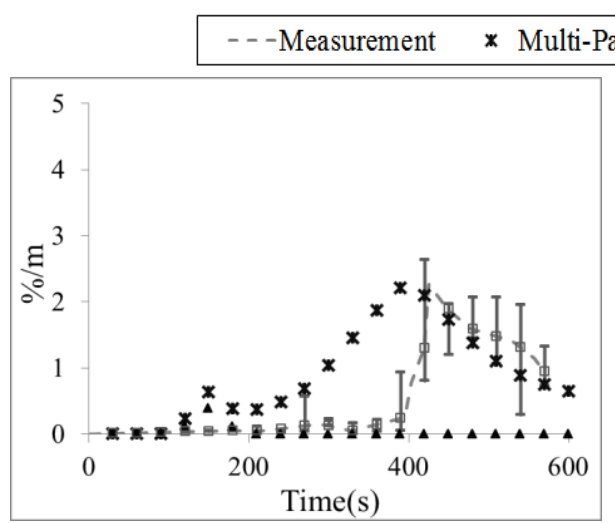

(a)

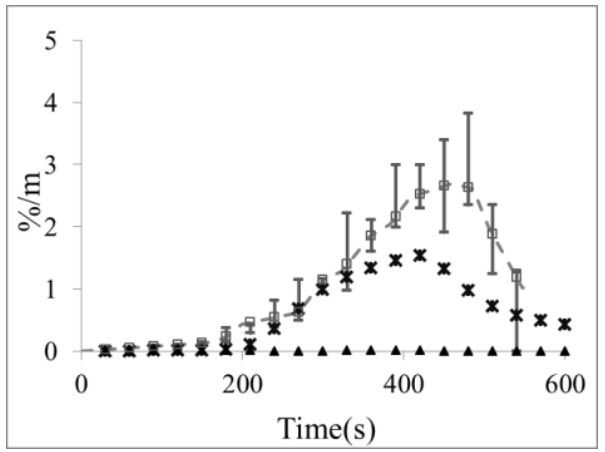

(b)

Fig. 10. The measured and predicted obscuration tendency at position of (a) Detector I, (b) Detector II.

The measured soot obscuration at Detector I was approximately $0.24 \% / \mathrm{m}$ at $390 \mathrm{~s}$ and then increased sharply to $2.1 \% / \mathrm{m}$ at 420 second. At Detector II, the measured obscuration started to increase gradually at 180 seconds and reached a peak value of $2.65 \% / \mathrm{m}$ at 450 seconds. The MPS model qualitatively captured the changing trends of obscuration at the two locations in spite of that the timings of the increases and peak values were not correctly predicted. At Detector I, the predicted obscuration increases gradually between 210 and 420 seconds and reached a peak value of $2.27 \% / \mathrm{m}, 8.1 \%$ higher than the measured peak. At Detector II, the predicted obscuration matches the measured value between 0 and 360 seconds, but the predicted peak value is only $1.45 \% / \mathrm{m}, 45 \%$ lower than the measured one. Considering the tests were not fully controlled and barriers for soot movement (stacked goods, racks, et al.) were unknown, only qualitative match of the model predictions with the measured obscuration can be expected. On the other hand, the Conventional Model predicted almost zero obscuration for both positions, which is far too low compared with the measurements.

\section{CONCLUSIONS}

The Multi-Particle-Size (MPS) model was developed to improve the prediction of soot movement by considering the influence of the uneven mass size distribution of soot particles of a combustible material on gravitational settling. To reduce the computational cost of the model, it is necessary to reduce the number of the soot particle groups that are originally derived from experiments. The soot particles are divided into a fewer number of groups by merging some of the original groups. In this study, three strategies for grouping soot particles were proposed and discussed by minimising the computational cost without significantly reducing the prediction accuracy. In order to examine the performance of these grouping strategies, the movement of soot particles produced from four materials in a large chamber was simulated using the three strategies. The simulation results show that using only a single representative size failed to produce reasonable predictions of soot concentration while the predictions produced using the other two strategies (Method 2 - utilizing three or more groups and Method 3 - utilizing three groups) matched reasonably well with the predictions produced using the 12 original soot particle classes obtained from the experiments. However, using Method 3 only three groups are required thereby reducing the computational costs compared to Method 2.

The MPS soot model with Method 3 was applied to simulate soot movement in a large industrial building with a high ceiling. While the Conventional Model failed to predict the downward movement of the soot 
layer, the MPS model predicted the soot descent phenomenon that was observed during the tests. The MPS model was able to predict the obscuration values at a number of positions reasonably accurately while the Conventional Model greatly under-predicted all of them.

\section{REFERENCES}

[1]. Chowdhury, N, Rowe, I and Sayer, G., "Fire statistics," Great Britain, 2011 to 2012, Department for Communities and Local Government, 2013.

[2]. Galea, E. R., Wang, Z., Veeraswamy, A., Jia, F., Lawrence, P. J., \& Ewer, J., "Coupled fire/evacuation analysis of the Station Nightclub fire," Proc of 9th IAFSS Symp, 2008, September, pp. 465-476. doi:10.3801/IAFSS.FSS.9-465

[3]. Rubini, P. A., Zhang, Q., \& Moss, J. B., "Simulation of visibility in smoke laden environments," InterFlam 2007, 11th International Conference on Fire Science and Engineering, London, UK, 2007.

[4]. Rinne, T., Hietaniemi, J., \& Hostikka, S., "Experimental validation of the FDS simulations of smoke and toxic gas concentrations," VTT, VTT Working Papers 1459-7683, Finland, 2007.

[5]. Pericleous, K. A., Worthington, D. R. E., \& Cox, G. "Smoke spread simulation in a covered sports stadium," IAFSS 4th Int Symp on Fire Safety, 1988, Tokyo, Japan

[6]. Galea E.R., Wang, Z., Veeraswamy, A., Jia, F., Lawrence, P., and Ewer, J., "Coupled Fire/Evacuation Analysis of the Station Nightclub Fire," Proceedings of 9th IAFSS Symposium Karlsruhe, Germany, 2008, ISNN 1817-4299, pp 465-476. doi:10.3801/IAFSS.FSS.9-465

[7]. Murakami, S., Kato, S., Nagano, S., \& Tanaka, Y., "Diffusion characteristics of airborne particles with gravitational settling in a convection-dominant indoor flow field," Ashrae Transactions, 1992, Volume 98(1), pp. 82-97.

[8]. Mulholland, G. W., "Smoke Production and Properties," The SFPE Handbook of Fire Protection Engineering, $\left(2^{\text {nd }} e d\right)$, DiNenno P.J. (ed.), National Fire Protection Association, Quincy, MA 02269, 1995, p. 2-258.

[9]. Hertzberg, T., \& Blomqvist, P., (2003) "Particles from fires-a screening of common materials found in buildings," Fire and materials 27(6): 295-314. doi:10.1002/fam.837

[10]. Fabian, T. Z., \& Pravinray, D. G., Smoke characterization project. Fire Protection Research Foundation/Underwriters Laboratories, Incorporated, 2007.

[11]. Butler, K. M., \& Mulholland, G. W., (2004) Generation and transport of smoke components, Fire Technology 40(2): 149-176. doi:10.1023/B:FIRE.0000016841.07530.64

[12]. Durst, F., Miloievic, D., \& Schönung, B., (1984) Eulerian and Lagrangian predictions of particulate two-phase flows: a numerical study, Applied Mathematical Modelling, 8(2): 101-115. doi:10.1016/0307-904X(84)90062-3

[13]. Gouesbet, G., \& Berlemont, A., "Eulerian and Lagrangian approaches for predicting the behaviour of discrete particles in turbulent flows," Progress in Energy and Combustion Science, 1998, Volume 25(2), pp. 133-159. doi:10.1016/S0360-1285(98)00018-5

[14]. Zhao, B., Yang, C., Yang, X., \& Liu, S., (2008) Particle dispersion and deposition in ventilated rooms: testing and evaluation of different Eulerian and Lagrangian models," Building and Environment 43(4): 388-397. doi:10.1016/j.buildenv.2007.01.005

[15]. Zhao, B., Zhang, Y., Li, X., Yang, X., \& Huang, D., (2004) Comparison of indoor aerosol particle concentration and deposition in different ventilated rooms by numerical method, Building and Environment 39(1): 1-8. doi:10.1016/j.buildenv.2003.08.002

[16]. Chen, F., \& Lai, A. C., (2004) An Eulerian model for particle deposition under electrostatic and turbulent conditions. Journal of aerosol science 35(1): 47-62. doi:10.1016/S0021-8502(03)00383-5 
[17]. Zhang, Z., \& Chen, Q., (2006) Experimental measurements and numerical simulations of particle transport and distribution in ventilated rooms, Atmospheric environment, 40(18): 3396-3408. doi:10.1016/j.atmosenv.2006.01.014

[18]. Hu, X., Wang, Z., Jia, F., Galea, E. R., \& Patel, M. K., (2011) Simulating smoke transport in large scale enclosure fires using a multi-particle-size model, Fire Safety Science 10: 445-458. doi: $\underline{10.3801 / \text { IAFFS.FSS.10-445 }}$

[19]. Floyd, J., Overholt, K., \& Ezekoye, O. (2014) Soot Deposition and Gravitational Settling Modeling and the Impact of Particle Size and Agglomeration. Fire Safety Science 11: 174. DOI: doi:10.3801/IAFSS.FSS.11-376

[20]. Hu, X., Modelling and simulation of soot generation and transport, University of Greenwich, $\mathrm{PhD}$ thesis, 2016

[21]. Rhodes, J., Smith, C., \& Stec, A. A., (2011) Characterisation of soot particulates from fire retarded and nanocomposite materials, and their toxicological impact, Polymer Degradation and Stability 96( 3): 277-284. doi:10.1016/j.polymdegradstab.2010.07.002

[22]. Gibbs, R. J., (1985) Estuarine flocs: their size, settling velocity and density, Journal of Geophysical Research: Oceans, 90(C2): 3249-3251. doi: 10.1029/JC090iC02p03249

[23]. Sippola, M. R., \& Nazaroff, W. W., "Particle deposition from turbulent flow: Review of published research and its applicability to ventilation ducts in commercial buildings," Lawrence Berkeley National Laboratory. 2002.

[24]. Soulsby, R. L., Manning, A. J., Spearman, J., \& Whitehouse, R. J. S., (2013) Settling velocity and mass settling flux of flocculated estuarine sediments, Marine Geology 339: 1-12. doi:10.1016/j.margeo.2013.04.006

[25]. Chen, F., Simon, C. M., \& Lai, A. C., (2006). Modeling particle distribution and deposition in indoor environments with a new drift-flux model. Atmospheric Environment, 40(2): 357-367. doi:10.1016/j.atmosenv.2005.09.044

[26]. Zhao, B., Chen, C., \& Tan, Z., (2009) Modeling of ultrafine particle dispersion in indoor environments with an improved drift flux model. Journal of Aerosol Science, 40(1): 29-43. doi:10.1016/j.jaerosci.2008.09.001

[27]. Alvin C.K.L, and William W.N, (2000) Modeling Indoor Particle Deposition from Turbulent Flow onto Smooth Surfaces, Journal of Aerosol Science 31: 436-476.

[28]. Elghobashi, S., (1994) On predicting particle-laden turbulent flows. Applied Scientific Research, 52(4): 309-329. doi:10.1007/BF00936835

[29]. Stec, A. A., \& Rhodes, J., (2011). Bench scale generation of smoke particulates and hydrocarbons from burning polymers. Fire Safety Science 10: 629-639. doi:10.3801/IAFSS.FSS.10-629

[30]. Hamins, A., "Chapter 3: Soot," Environmental implications of combustion processes, Puri, I. K. (ed), CRC Press, 1993.

[31]. Blomqvist, J., "Smoke detection in buildings with high ceilings," SP Swedish National Testing and Research Institute, Sweden, 2003.

[32]. Kittelson, D., Watts, W., \& Johnson, J., "Diesel Aerosol Sampling Methodology-CRC E-43," Coordinating Research Council, 2002.

[33]. Thermo, K., “Generator set range SG-3000 \& SG-4000 series,” Ingersoll-Rand Company Limited, 2014.

[34]. He, M., Jiang, Y., \& Perez, C., "Use FDS to Assess Effectiveness of Air Sampling Smoke Detection in Large Open Spaces," Vision Fire \& Security, 2004. 